\title{
Role of Genetic Factors in the Course of Echinococcosis Disease
}

\author{
Lukmanova GI ${ }^{1 *}$, Nartailakov $\mathrm{MA}^{2}$ and Lukmanov $\mathrm{MI}^{3}$ \\ ${ }^{1}$ Professor of the Department of Biology, Bashkir state medical University, Russia \\ ${ }^{2}$ Professor, Head of the Department of General Surgery, Bashkir state medical University, Russia \\ ${ }^{3}$ Assistant of the Department of General surgery, Bashkir state medical university, Russia
}

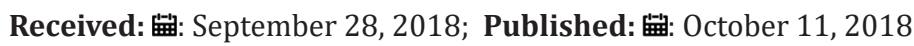

*Corresponding author: Lukmanova GI, Professor of the Department of Biology of Bashkir state medical University, 450005, Ufa, Lenin 3, Russia

\begin{abstract}
For several years, we conducted a study of the role of genetic factors in the pathogenesis of echinococcosis among residents of the Republic of Bashkortostan. The associations of polymorphic allele's genes of cytochrome P-450 (CYP1A1, CYP1A2), glutathione-S-transferases (GSTM, GSTT), cytokines (TNFA), the specificities of Human Leukocyte Antigens (HLA-A, B, DRB1, DQB1) and blood groups AB0 with echinococcosis have been studied. Based on the analysis of the results, it was shown that genetic factors play a role in the invasion of Echinococcus granulosus with genotype G1 (common, domestic sheep).
\end{abstract}

Keywords: Genetic Factors; Echinococcosis; Albendazole; Cytochrome P450; Polymorphic; Sulfoxide; Enzymes; Catalytic; Patients; Helminthiasis

\section{Introduction}

For several years, we conducted a study of the role of genetic factors in the pathogenesis of echinococcosis among residents of the Republic of Bashkortostan. They considered that the systems most interested in the development of echinococcosis, which ensure the biological individuality of the organism. These are genes involved in the recognition of "foreign" and the neutralization of foreign toxins (including products of helminth metabolism). Therefore, the genes of the immune response and detoxification of xenobiotics were investigated. The associations of polymorphic allele's genes of cytochrome P-450 (CYP1A1, CYP1A2), glutathione-S-transferases (GSTM, GSTT), cytokines (TNFA), the specificities of Human Leukocyte Antigens (HLA-A, B, DRB1, DQB1) and blood groups AB0 with echinococcosis have been studied. Based on the analysis of the results, it was shown that genetic factors play a role in the invasion of Echinococcus granulosus with genotype G1 (common, domestic sheep). For example, we did not find any cases of echinococcosis in carriers of HLA-B27, which agrees with the studies of Shcherbakov A.M. and Monge-Barredo PA [1]. Comparative analysis showed that in healthy people (from the control group) antigens were more common: HLA-A9; A10; B5; B12, relating to the Original Broad Specificities. In the group of patients with echinococcosis, there were more people with antigens A24 (9); A26 (10); B51 (5); B44 (12), relating to the Splits. Analysis of genetic factors is of practical importance.
For example, we used a genetic study of polymorphism * $1 \mathrm{~F}$ (C-163A) of the cytochrome P450 CYP1A2 gene to determine the dose of albendazole. Albendazole in human liver rapidly turns into albendazole-sulfoxide, which has anthelmintic activity against cestodes and nematodes. Then albendazole-sulfoxide is metabolized by enzymes into albendazole-sulfone (which does not have an anthelmintic effect). At this stage of the biotransformation, various enzymes take part, including cytochrome P450 - CYP1A2. It is known that the alleles of the gene CYP1A2 significantly affect the catalytic activity of cytochrome P450 [2,3]. The genotype AA corresponds to ultraextensive metabolizers (UM). CC and AC genotypes (A gene allele is recessive) - determine the normal metabolic rate (extensive metabolizers, EM). In patients with liver echinococcosis with genotype AA and phenotype - UM, albendazole-sulfoxide is rapidly metabolized in will have a short therapeutic effect. Persons with this genotype were recommended chemotherapy in the maximum tolerated dose of albendazole. Patients with the CC and AC genotype who had the EM phenotype were prescribed the prevention of relapse at the standard minimum dose. It is known that cytochromes CYP1A1 and CYP1A2 are key enzymes involved in the detoxification of aromatic hydrocarbons contained in cigarette smoke and in the metabolism (by 90\%) of caffeine [3]. Based on these data, it was concluded that the use of coffee and cigarettes is undesirable in the treatment of albendazole. Thus, genetic factors 
in the pathogenesis of echinococcosis are important and can be considered in the treatment of this helminthiasis.

\section{References}

1. AM Shcherbakov, PA Monge Barredo (1989) Distribution of antigens of the HLA system among patients with echinococcosis / Medical parasitology and parasitic diseases. 6: 5-8.

\section{ISSN: 2574-1241}

DOI: $10.26717 / B J S T R .2018 .09 .001879$

Lukmanova GI. Biomed J Sci \& Tech Res

(C) (i) This work is licensed under Creative

Submission Link: https://biomedres.us/submit-manuscript.php
2. Ya G Novitskaya, VP Zherdev, AO Viglinskaya, AA Litvin (2014) Isoform CYP1A2 as an integral part of the superfamily of cytochromes P-450 / Pharmacokinetics and pharmacodynamics 1: 4-7.

3. MP Marques, OM Takayanagui, VL Lanchote (2002) Albendazole metabolism in patients with neurocysticercosis: antipyrine as a multifunctional marker drug of cytochrome P450 / Brazil. J Med Biol Res 35(2): 261-269.

\begin{tabular}{ll} 
BIOMEDICAL & Assets of Publishing with us \\
RESEARCHES & - Global archiving of articles \\
& - Immediate, unrestricted online access \\
\hline https://biomedres.us/
\end{tabular}

